\title{
PERCEPÇÃo DOS RESIDENTES SOBRE A ARBORIZAÇÃo DA CIDADE DE SÃO JOSÉ DE PIRANHAS-PB ${ }^{1}$
}

\author{
Norono Pedrosa Lacerda ${ }^{2}$, Patrícia Carneiro Souto ${ }^{3}$, Rondynelli Sobral Dias ${ }^{4}$, Lauter Silva \\ Souto $^{5}$, Jacob Silva Souto ${ }^{6}$
}

(recebido em 09.10.2010 e aceito para publicação em 15.12.2010)

\section{RESUMO}

A qualidade ambiental urbana é um conjunto de condições materiais, sociais e psicológicas que maximizam o bem-estar humano nas cidades, melhorando a qualidade de vida da população. O presente estudo teve por objetivo realizar o diagnóstico da percepção dos moradores sobre a arborização na zona urbana de São José de Piranhas (PB), de modo a obter informações sobre as necessidades, críticas e sugestões para elaboração de futuros planos de gestão. Para isso foram escolhidos sete bairros onde foram aplicados vinte questionários em cada bairro, de forma aleatória, perfazendo um total de 140 entrevistas. Os resultados obtidos indicaram que $66,0 \%$ dos entrevistados, relataram como vantagem da presença da arborização o conforto térmico e 72,0\% declararam como desvantagem, a sujeira de ruas e calçadas. Dos entrevistados, 59,8\% consideraram a arborização existente razoável e $89,7 \%$ recusaram a contribuir com qualquer valor. Por meio da pesquisa de opinião percebeu-se que a baixa valoração da arborização urbana pelos munícipes entrevistados refletiu-se no pouco interesse em cooperar com a melhoria da arborização, não só financeiramente, mas pela omissão.

Palavras-chave: valoração, participação social, zona urbana

\footnotetext{
1 Parte da Monografia do primeiro autor apresentada a Coordenação de Agronomia do Centro de Ciências e Tecnologia Agroalimentar da Universidade Federal da Paraíba, campus de Pombal (PB). 2 Engenheiro Agrônomo, Universidade Federal de Campina Grande, Campus de Pombal. E-mail: noronopedrosa@hotmail.com

3 Professor da Unidade Acadêmica de Engenharia Floresta, Universidade Federal de Campina Grande, Campus de Patos. Av. Universitária, sn, Bairro Santa Cecília, Patos-PB. CEP: 58708-110. Email: pcarneirosouto@yahoo.com.br

4 Engenheiro Agrônomo, Universidade Federal de Campina Grande, Campus de Pombal. E-mail: noronopedrosa@hotmail.com

5 Professor da Unidade Acadêmica de Engenharia Floresta, Universidade Federal de Campina Grande, Campus de Patos. Av. Universitária, sn, Bairro Santa Cecília, Patos-PB. CEP: 58708-110. 6 Professor da Unidade Acadêmica de Agronomia e Tecnologia de Alimentos, Universidade Federal de Campina Grande, Campus de Pombal-PB.
}

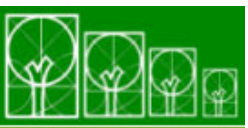

S $\cdot \mathbf{B} \cdot \mathbf{A} \cdot \mathbf{U}$ Soc. Bras. de Arborização Urbana 


\section{PERCEPTION OF RESIDENTS REGARDING TREE PLANTING IN \\ SAO JOSÉ DE PIRANHAS}

\section{ABSTRACT}

The urban environmental quality is a gathering of material, social, and psychological conditions that maximizes human welfare in the cities, improving the population's quality of life. This work aimed to perform the diagnosis of residents perception on the urban tree planting in Sao Jose de Piranhas, trying to get information about its needs, as well as to listen to opinions and suggestions to elaborate future management plans. For doing this, seven neighborhoods were selected, where twenty questionnaires were applied by random sampling, totaling 140 people interviewed. The results obtained indicated that $66.0 \%$ of the people interviewed see some advantage in urban tree planting and 72.0\% reported it as a disadvantage: dirt streets and sidewalks. 59.8\% considered the current tree planting reasonable, and $89.7 \%$ refused to give any opinion. Through the survey it was noticed that the low valuation of urban tree planting by the residents interviewed reflected on the little interest in cooperating with the improvement of tree planting, not only financially, but by omission.

Keywords: valorization, social participation, urban zone. 


\section{INTRODUÇÃO}

A vegetação urbana constituída pelas árvores nas calçadas, canteiros centrais, parques e praças públicas e também pelos quintais e jardins é o componente ambiental mais visível e provavelmente o que primeiro pressiona a população local ou visitante.

Atualmente, a ocupação em massa das cidades que nem sempre possuem um planejamento urbano, contribui para um crescimento desordenado, com destruição desenfreada dos recursos naturais existentes, influenciando diretamente na qualidade de vida da população. De acordo com Batista (2006), a maioria das cidades não consegue manter um equilíbrio harmônico entre seu crescimento populacional e geográfico com o meio ambiente.

A paisagem urbana deve integrar o homem com o meio ambiente e satisfazer às suas necessidades. No entanto, em decorrência do crescimento muitas vezes inadequado das cidades, o meio ambiente urbano vem sofrendo diversas modificações, que contribuem para a insatisfação da população (SILVA et al., 2008).

Para um melhor planejamento e compreensão do ambiente urbano, fazem-se necessários estudos que enfoquem a percepção da população em relação ao meio ambiente, pois no uso cotidiano dos espaços, dos equipamentos e serviços urbanos, a população sente diretamente o impacto da qualidade ambiental (RIO \& OLIVEIRA, 1999).

Trigueiro (2003) define percepção ambiental como sendo uma tomada de consciência o ambiente pelo "homem", ou seja, perceber o ambiente que se está localizado, aprendendo a proteger e cuidar dele da melhor forma possível.

A percepção da população quanto aos benefícios trazidos por uma arborização adequada das áreas urbanas tem sido utilizada em alguns bairros ou cidades do Brasil. Assim, a educação ambiental poderá ajudar as pessoas a perceberem mais o seu meio, conscientizando-se da necessidade de preservação. Esta nova visão do seu meio só poderá se realizar através do conhecimento, entendimento, integração e, sobretudo do respeito pela natureza que os rodeia.

Segundo Faggionato (2007), o estudo da percepção ambiental é de fundamental importância, onde por meio dele é possível conhecer a cada um dos indivíduos envolvidos, facilitando a realização de um trabalho com bases locais, partindo da realidade do público alvo, sabendo como os indivíduos percebem o ambiente em que vivem suas fontes de satisfação e insatisfação.

Dentro da proposição ressaltada pela UNESCO em 1973, "uma das dificuldades para a proteção dos ambientes naturais está na existência de diferenças nas percepções dos

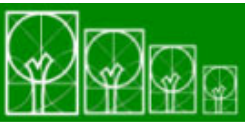

$\mathbf{S} \cdot \mathbf{B} \cdot \mathbf{A} \cdot \mathbf{U}$ Soc. Bras. de Arborização Urbana 
valores e da importância dos mesmos entre os indivíduos de culturas diferentes ou de grupos sócio-econômicos que desempenham funções distintas, no plano social, nesses ambientes". Neste contexto o termo "Percepção Ambiental" passa a ser usado no sentido amplo de "uma tomada de consciência do ambiente pelo homem" (MAROTI, 2005).

Malavasi \& Malavasi (2001) salientam que as propriedades inerentes ao bem-estar do homem citadino estão vinculadas ao componente vegetal que faz parte dos aglomerados urbanos. Plantar árvores nas cidades significa assim atender a dupla natureza humana: a biológica e a cultural. No entanto, a percepção da arborização urbana pela população humana tem sido relegada a um plano secundário pelos administradores e técnicos responsáveis. Portanto, faz-se necessário, para um eficiente planejamento e manutenção da arborização urbana, considerar a percepção da população.

O conhecimento da percepção é um instrumento que a administração municipal pode utilizar no planejamento e gestão de áreas verdes, atendendo a população e também para o estabelecimento de programas de Educação Ambiental.

Considerando a importância da arborização urbana na qualidade de vida da população este trabalho teve como objetivo realizar o diagnóstico da percepção dos moradores sobre a arborização na zona urbana de São José de Piranhas (PB), de modo a avaliar o grau de conscientização seus residentes.

\section{MATERIAIS E MÉTODOS}

O estudo foi realizado em setembro de 2008 na cidade de São José de Piranhas (PB), coordenadas geográficas $7^{\circ} 7^{\prime} 15^{\prime \prime} \mathrm{S}$ e $38^{\circ} 30^{\prime} 7^{\prime \prime} \mathrm{W}$, localizada na mesorregião do Sertão Paraibano, microrregião de Cajazeiras. A área total do município é de $697,89 \mathrm{~km}^{2}$, e a população segundo dados do IBGE (2008) contabiliza 18.898 habitantes, sendo a população urbana de 9.790 habitantes

O clima da região do tipo BSh semiárido, caracterizada por temperatura média anual superiores a $25^{\circ} \mathrm{C}$, com índice pluviométrico de $700 \mathrm{~mm}$.e chuvas irregulares. Quanto ao tipo de solo, no município ocorrem associações de Neossolos Litólicos, Luvissolos, Argissolos e Afloramentos de rochas (EMBRAPA, 2006).

$\mathrm{Na}$ avaliação da percepção da população sobre a arborização urbana, foi utilizado um questionário previamente elaborado com dez perguntas, seguindo a metodologia descrita por Malavasi \& Malavasi (2001). A definição dos pontos de amostragem foi estabelecida no sentido leste-oeste, norte-sul, dentro dos limites da zona urbana

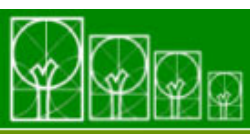

$\mathbf{S} \cdot \mathbf{B} \cdot \mathbf{A} \cdot \mathbf{U}$ Soc. Bras. de Arborização Urbana 
reconhecida pela prefeitura, de modo a detectar a opinião dos moradores em todos os limites da cidade. Para coleta dos dados foram selecionados 7 bairros, onde em cada ponto de amostragem, realizou-se aleatoriamente a aplicação de vinte questionários aos residentes. Os entrevistados foram residentes de ambos os lados das ruas e os questionários foram aplicados somente a um residente por domicílio.

Variáveis como sexo, idade e escolaridade, serviram como parâmetro de representatividade da população. Dessa forma, as diversas camadas da população foram representadas na pesquisa. A entrevista relacionou os seguintes assuntos: número de moradores por residência, grau de escolaridade, grau de arborização da rua, vantagens e desvantagens apresentadas pela arborização, encaminhamento de necessidades a órgãos públicos e privados (Prefeitura municipal, companhias elétricas e telefônicas, etc.) referentes à implantação e manutenção da arborização, forma de colaboração por parte dos moradores a manutenção e melhoria da arborização, indicação de espécies que estes desejariam que fossem implantadas e se estariam dispostos a colaborar financeiramente com a arborização da rua e quanto dariam, caso esta fosse implantada.

Após a realização das entrevistas foi feita a compilação e análise dos dados obtidos, através de planilhas informatizadas.

\section{RESULTADOS E DISCUSSÃo}

A partir dos resultados obtidos pela pesquisa de opinião, obtiveram-se algumas informações sobre o que os munícipes acham com relação à arborização da cidade. Foram entrevistados 140 residentes, correspondendo a 1,4\% da população de São José de Piranhas, cujo perfil social dos entrevistados encontra-se na tabela 1. 
TABELA 1 - Perfil social dos entrevistados na cidade de São José do Piranhas (PB)

TABLE 1 - Social profile of people interviewed in Sao Jose de Piranhas.

\begin{tabular}{lc}
\hline Gênero & Freqüência \\
\hline Masculino & 60,8 \\
Feminino & 39,2 \\
\hline Total & $\mathbf{1 0 0}$ \\
\hline & \\
Faixa etária & 26,6 \\
\hline $15-20$ & 22,7 \\
$21-30$ & 25,7 \\
$31-40$ & 18,5 \\
$41-50$ & 6,5 \\
Acima de 50 & $\mathbf{1 0 0}$ \\
\hline Total & \\
\hline & \\
Escolaridade & 31,9 \\
\hline Fundamental completo & 49,5 \\
Médio completo & 8,3 \\
Superior completo & 10,3 \\
Sem formação & $\mathbf{1 0 0}$ \\
\hline Total & \\
\hline & \\
Atividade & 26,8 \\
\hline Doméstica/agrícola & 40,2 \\
Profissional liberal & 5,2 \\
Funcionário público & 27,8 \\
Estudante & $\mathbf{1 0 0}$ \\
\hline Total &
\end{tabular}

A discriminação dos entrevistados por gênero revelou que a maioria dos participantes era do sexo masculino e apenas $39,2 \%$ do sexo feminino, cuja faixa etária da maioria variou entre $15-20$ a $30-40$ anos. Observou-se que $49,5 \%$ dos participantes tinham ensino médio completo, $31,9 \%$ apenas o fundamental completo, $8,3 \%$ com curso superior completo e 10,3\% não tinha nenhuma formação. O tipo de atividade mais citada pelos entrevistados foi profissional liberal com $40,2 \%$ e isso é justificado, já que a maioria dos entrevistados foram homens. Em seguida vêm as atividades estudante, doméstica e funcionário público com $27,8 \%, 26,8 \%$ e 5,2\%, respectivamente.

No presente estudo, 59,8\% dos munícipes classificaram a arborização da cidade como razoável $36,1 \%$ como muita e $4,1 \%$ como pouca (Figura 2). É interessante ressaltar que a maioria da população percebe a carência de árvores no perímetro urbano. 


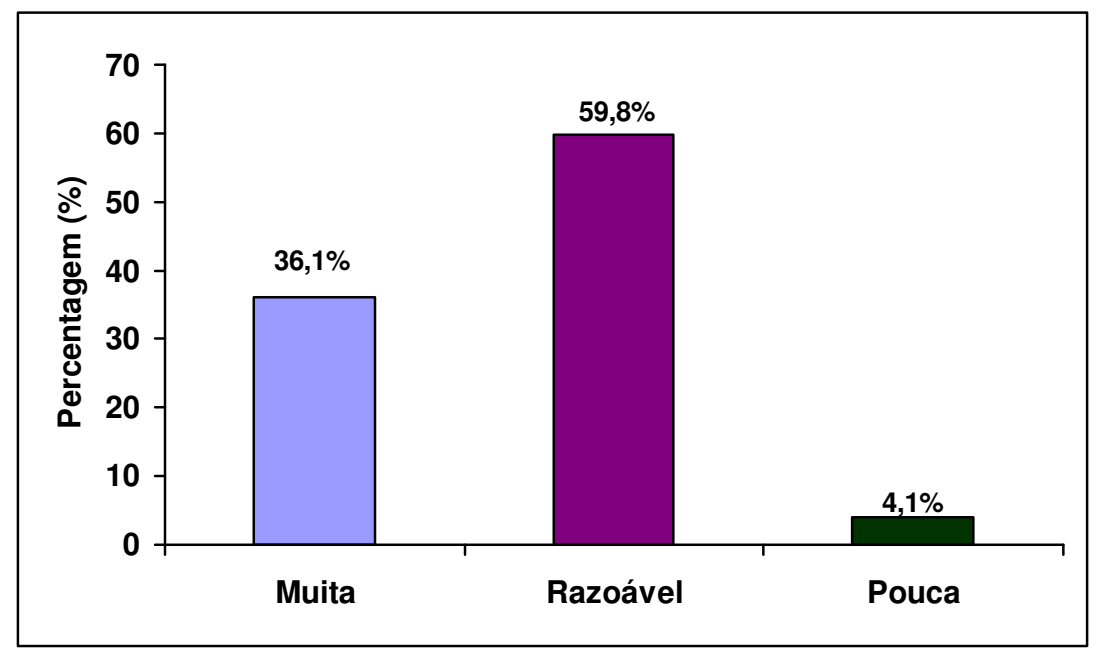

FIGURA 2 - Percepção dos moradores de São José de Piranhas (PB) quanto à arborização urbana

FIGURE 2 - Perception of residents of Sao Jose de Piranhas regarding urban tree planting

Segundo Roppa et al. (2007), este tipo de avaliação tende a ser muito subjetiva, dependendo em grande parte da maior ou menor vivência do morador no local, pelo fato que muitos tendem a avaliar a arborização de sua rua ou mesmo a que se encontra enfrente a sua casa.

Questionados sobre vantagem ou desvantagem da arborização urbana da cidade, $66 \%$ dos entrevistados mencionaram que a arborização proporciona redução de calor, 32\% apontaram o sombreamento, $2 \%$ citaram a presença de flores e nenhum entrevistado citou a redução de ruídos (Figura 3). As vantagens citadas pelos munícipes são justificadas devido aos rigores climáticos da região que na maior parte do ano apresenta clima quente e seco, com temperaturas superiores a $25^{\circ} \mathrm{C}$.

Resultados semelhantes foram obtidos por Malavasi \& Malavasi (2001), avaliando a percepção de moradores em Marechal Rondon (PR) e por Roppa et al. (2007), em estudo realizado em bairro de Santa Maria (RS). As vantagens citadas por moradores segundo Roppa et al. (2007) estão relacionadas aos benefícios que a arborização proporciona na qualidade do microclima urbana, principalmente no verão, onde a ocorrência de altas temperaturas impulsiona a população a buscar diferentes meios que proporcionem maior conforto térmico. Isso é ratificado por Lira Filho et al. (2009), ao afirmarem que para a realidade do Sertão paraibano é imprescindível a presença de massa arbórea para propiciar melhorias microclimáticas. 


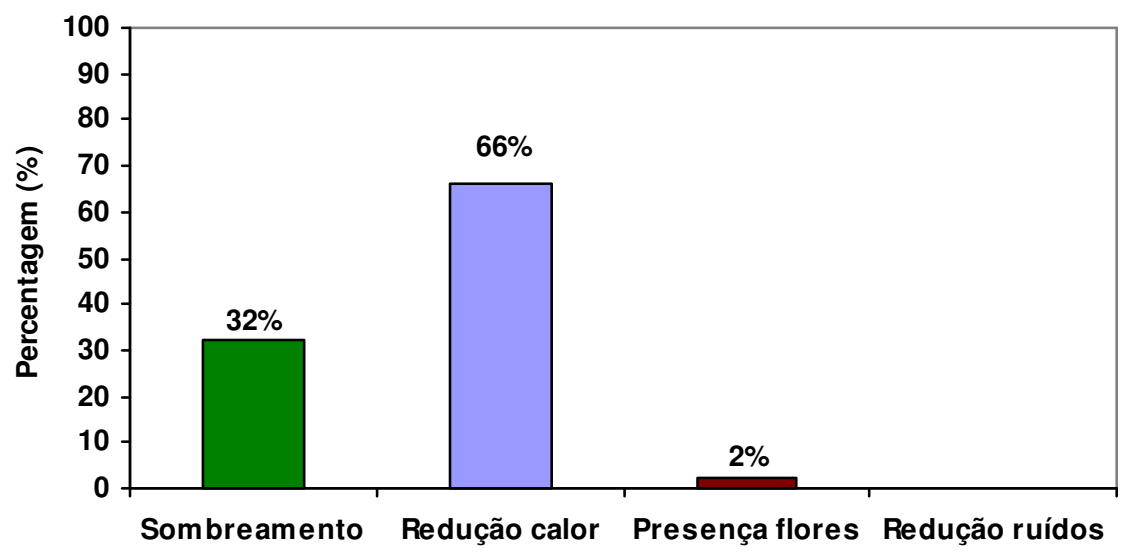

FIGURA 3 - Vantagens da arborização urbana de São José de Piranhas (PB), segundo os entrevistados

FIGURE 3 - Benefits of urban tree planting in Sao Jose de Piranhas according to people interviewed

Para Batista (2006), muito além de desempenhar apenas um papel estético na composição urbana, as árvores têm funções múltiplas que podem contribuir de maneira efetiva na promoção de melhorias na qualidade ambiental das cidades. Podendo atuar na melhoria da qualidade do ar, nas questões de melhoramento climático, na qualidade da ambientação das áreas verdes, no quesito da redução da poluição sonora e ambiental, na preservação dos fundos de vales.

A respeito das desvantagens da arborização apontadas pelos moradores as mais freqüentes foram sujeira de ruas e calçadas com $72,2 \%$ e redução da iluminação pública com $12,4 \%$ (Figura 4 ).

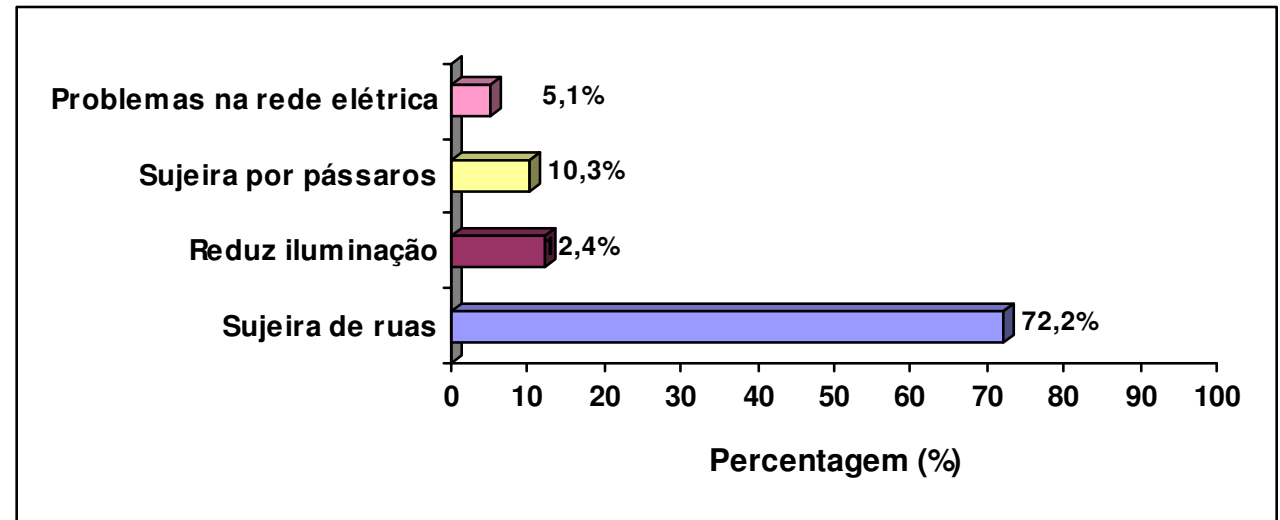

FIGURA 4 - Desvantagens da arborização urbana de São José de Piranhas (PB), citadas pelos entrevistados

FIGURE 4 - Disadvantages of urban tree planting in Sao Jose de Piranhas according to people interviewed 
Malavasi e Malavasi (2001), em um estudo onde avaliaram a arborização urbana pelos residentes em Mal. Cândido Rondon- PR obtiveram dados de que $56 \%$ dos entrevistados atribuem como desvantagem da arborização a sujeira de ruas e calçadas, seguida pela redução na iluminação pública e problemas com a rede elétrica ambas com $8 \%$.

Ao serem argüidos sobre quem seria responsável pela arborização da cidade, 46,4\% dos entrevistados disseram que era o próprio morador, $39,2 \%$ atribuíram à prefeitura e apenas 14,4\% citaram o profissional contratado pelo morador (Figura 5a). Quando questionados sobre a quem encaminhar reclamação relacionada à arborização urbana, $60,8 \%$ atribuíram a prefeitura, 39,2\% não sabem a quem reclamar e nenhum entrevistado citou a companhia elétrica (Figura 5b).

A

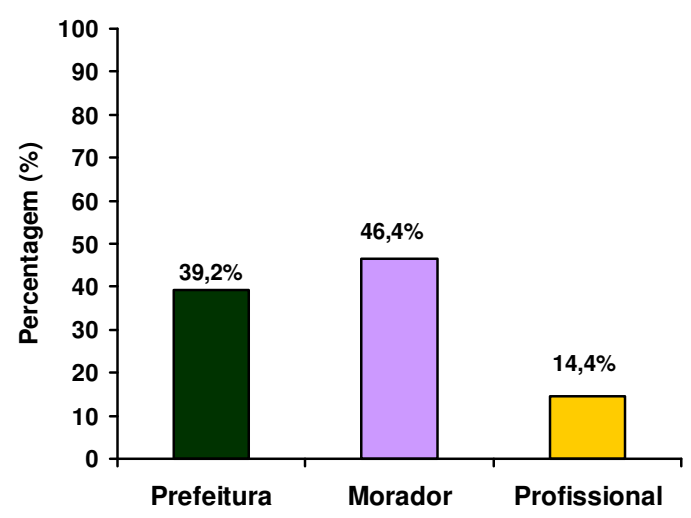

B

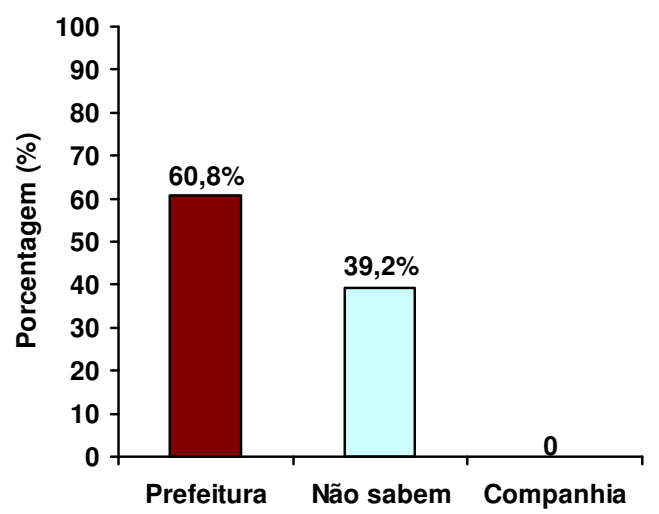

FIGURA 5- Responsável pela arborização urbana (a) e responsabilidade para o encaminhamento de reclamação (b), segundo os entrevistados de São José de Piranhas (PB)

FIGURE 5 - Responsible for urban tree planting (a) and responsibility for the guiding of claim (b), according to people interviewed in Sao Jose de Piranhas

Esses dados evidenciam a arborização urbana deve fazer parte dos programas de governo das prefeituras, já que a qualidade do meio ambiente vai refletir no bem estar e na qualidade de vida dos munícipes. Confrontando com a resposta anterior (Figura 5a), percebe-se uma controvérsia, pois, os entrevistados responderam que são responsáveis pela arborização e, em contrapartida, atribui à prefeitura a responsabilidade de resolver os problemas relacionados à arborização urbana. É importante que o governo municipal planeje e implante um programa de arborização na cidade, sendo assim, o responsável, tendo a população como fiel parceira na manutenção desse valioso bem público.

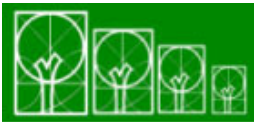

$\mathbf{S} \cdot \mathbf{B} \cdot \mathbf{A} \cdot \mathbf{U}$ Soc. Bras. de Arborização Urbana 
$\mathrm{Na}$ realidade, o que se observa na maioria dos estudos dessa natureza é que a população não sabe a que recorrer quando tem algum problema relacionado à arborização e, muitas vezes, toma decisões que nem sempre são as mais apropriadas, seja na implantação ou na retirada de árvores. Segundo Roppa et al. (2007) há uma grande possibilidade de insucesso por falta de adesão da população, devido ao desconhecimento destes órgãos dos reais anseios e necessidades da população do local.

O papel da população como importante parceiro na implantação e manutenção da arborização urbana é confirmado na Figura 6, onde 39,2\% dos entrevistados responderam que colaboram com a arborização urbana plantando árvores, 28,9\% não danificando, 4,1\% não maltratando e $27,8 \%$ disseram que nada fazem. No entanto, os percentuais dos que afirmaram que nada fazem apresentou valores elevados, e esta postura pode esta relacionada com a falta de percepção da importância da arborização na melhoria da qualidade de vida local. Diante do exposto é imprescindível a realização de campanhas de sensibilização do poder público de modo a reverter esse cenário, transformando os munícipes em parceiros.

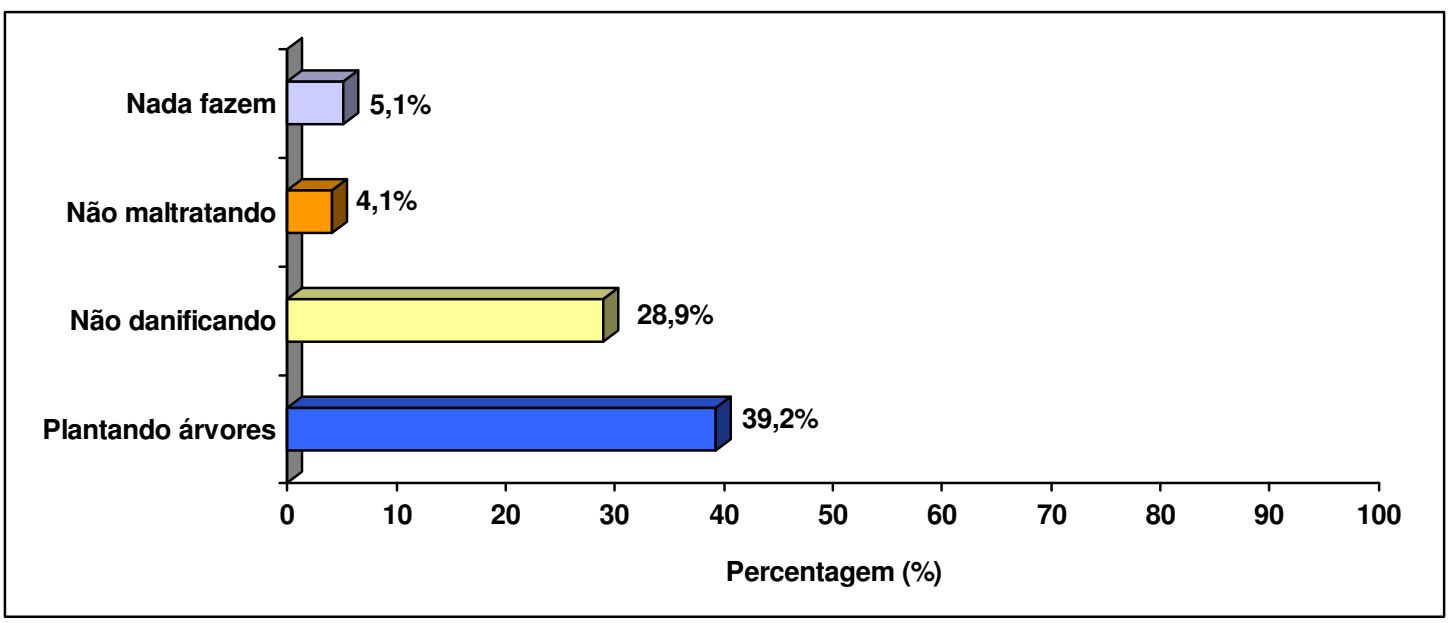

FIGURA 6 - Modos de colaboração dos munícipes à arborização urbana de São José de Piranhas (PB), relatados pelos os entrevistados

FIGURE 6 - Residents ways of contributing to the urban tree planting in Sao Jose de Piranhas told by people interviewed

Para Lira Filho et al. (2009) sensibilizar a população alvo para atuarem na arborização participativa é um processo de educação ambiental e isso se consegue utilizando-se dos mais variados meios (oficinas para construção do processo participativo com os atores sociais, divulgação do projeto na mídia convencional e alternativa). Em um projeto piloto desenvolvido em duas pequenas cidades do semiárido da Paraíba os autores observaram nas oficinas de construção do Plano de Arborização Participativa uma grande

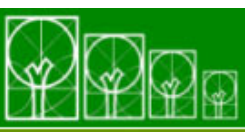

$\mathbf{S} \cdot \mathbf{B} \cdot \mathbf{A} \cdot \mathbf{U}$ Soc. Bras. de Arborização Urbana 
receptividade por parte da população alvo e das instituições envolvidas na arborização urbana. Esse estudo revelou que a introdução do processo participativo é plenamente viável na arborização em cidades de pequeno porte e que a população tem se sensibilizado bastante no que concerne aos benefícios sobre a presença da massa arbórea nas cidades.

O envolvimento concreto da população no processo de arborização urbana constitui segundo Paiva e Gonçalves (2002) um ato de cidadania, contribuindo para a construção de uma consciência crítica sobre as questões ambientais urbanas. Desse modo, o envolvimento da população na escolha e organização do processo de arborização urbana contribuirá para que os munícipes participantes sejam multiplicadores de informações, resultando em mudanças de conduta em relação aos recursos naturais urbanos.

Quando questionados sobre o tipo de vegetal que escolheriam para serem utilizados na arborização urbana, $89,7 \%$ dos entrevistados preferiram a implantação de árvores (Figura 7), resposta quase que unânime o que confirma a necessidade de melhoria na arborização da cidade, minimizando os efeitos do clima quente e seco que castiga os municípios sertanejos a maior parte do ano.

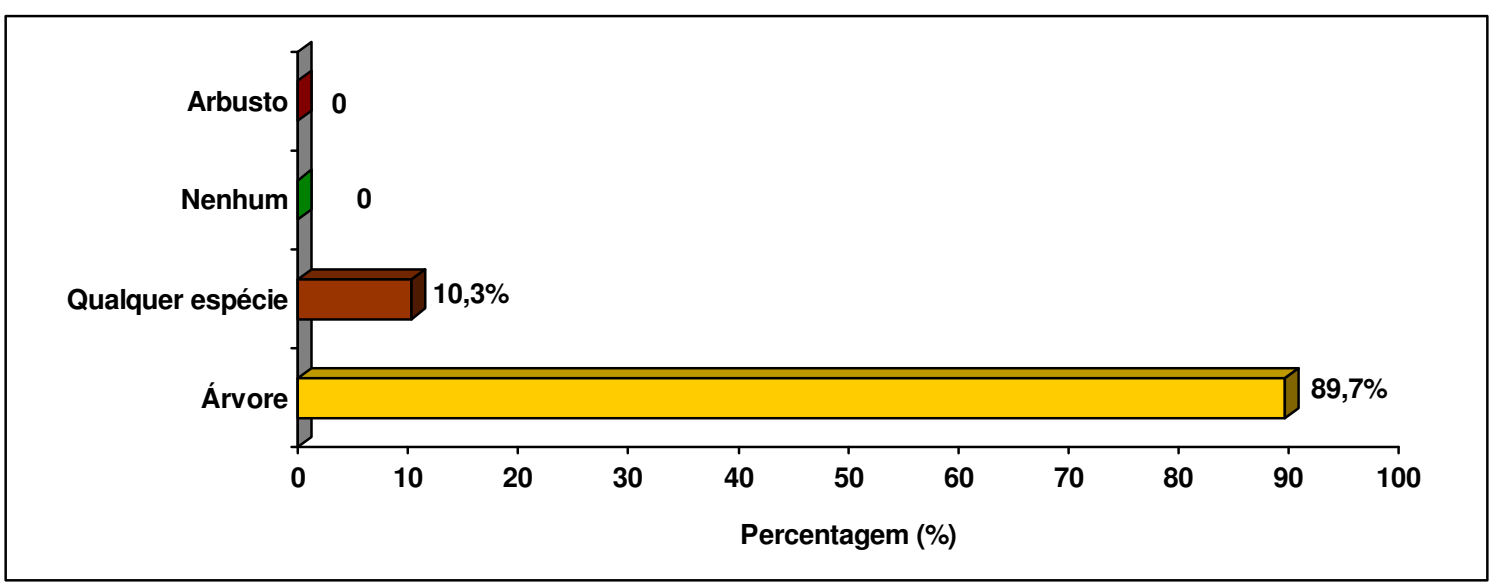

FIGURA 7 - Preferência dos moradores quanto ao tipo vegetal a ser utilizado na arborização urbana de São José de Piranhas (PB)

FIGURE 7 - Preference of the inhabitants regarding the vegetal type to be used in the urban tree planting in Sao Jose de Piranhas

A escolha da espécie a ser plantada é segundo Guzzo (2005), o aspecto mais importante a ser considerado, sendo extremamente relevante que seja considerado o espaço disponível que se tem a presença ou ausência de fiação aérea e de outros equipamentos urbanos, largura da calçada e recuos, o que está vinculado ao conhecimento do porte da espécie a ser utilizada.

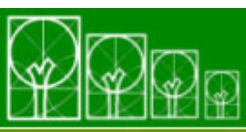

$\mathbf{S} \cdot \mathbf{B} \cdot \mathbf{A} \cdot \mathbf{U}$ Soc. Bras. de Arborização Urbana 
Quanto aos motivos de não plantar árvores $37,2 \%$ dos moradores atribuíram ao risco com a viação elétrica; $20,6 \%$ não plantam porque a casa é alugada ou provoca danos à calçada (Figura 8).

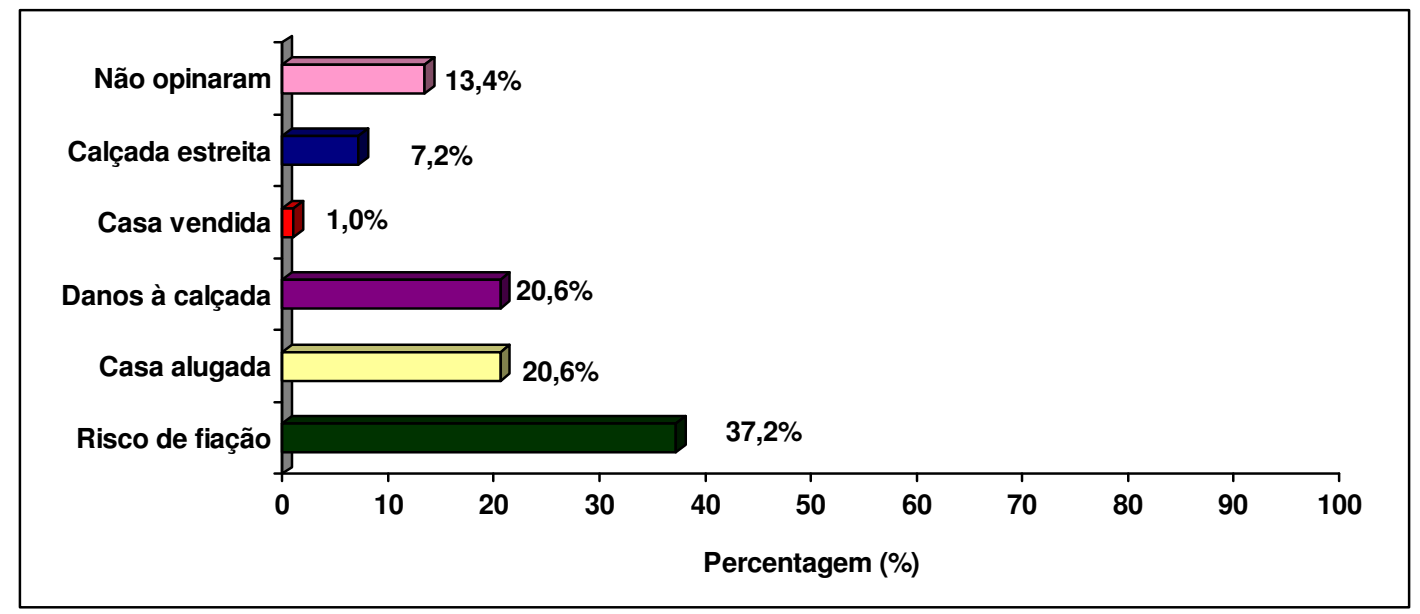

FIGURA 8 - Motivos que levam o morador a não plantar árvore na zona urbana de São José de Piranhas (PB), na visão dos entrevistados

FIGURE 8 - Reasons that take the inhabitant not to plant a tree in the urban zone of Sao Jose de Piranhas according to people interviewed

As respostas demonstram que não existe um planejamento quanto à escolha da melhor espécie a ser plantada, de modo a não interferir na rede elétrica ou causar danos às calçadas, o que leva, muitas vezes, os moradores a desistirem de plantar árvores na frente de suas casas. Em relação à fiação elétrica Lira Filho et al. (2009) salientam que para a realidade do Sertão paraibano, a concessionária de energia elétrica não disponibiliza de tecnologia de proteção da fiação em relação aos galhos das árvores. Apesar dessa negligência da concessionária e considerando importância da vegetação arbórea para a região, os autores recomendam o uso de árvores de pequeno porte no lado da rua com fiação aérea.

Com isso, verifica-se uma resistência cada vez maior da cooperação de moradores na implantação ou manutenção da arborização de suas ruas. Não plantar por porque a casa é alugada indica que essa parcela da população tem pouco conhecimento sobre a importância ambiental da vegetação e que o plantio de árvores resulta em melhoria não só para aquele morador ou local restrito, mas, proporciona benefícios socioambientais em toda a zona urbana.

Outro aspecto relevante refere-se à necessidade dos munícipes conhecerem e debaterem mais sobre as questões ambientais para que despertem 0 interesse pela implantação de mais áreas verdes no município. Em trabalho desenvolvido por Lira Filho et 
al. (2009) no sertão da Paraíba, os autores detectaram que na região os Poderes Públicos Municipais têm sido cobrados pela sociedade civil organizadas para a elaboração de Planos Diretores de Arborização. Tal fato demonstra certo avanço de consciência ambiental tanto por parte da população urbana quanto dos seus administradores.

Ao questionar os entrevistados sobre a possibilidade de contribuírem financeiramente para a manutenção da arborização urbana (Figura 9), 83,5\% disseram que não contribuiriam, $7,2 \%$ estavam dispostos a contribuir com $R \$ 0,50$, e o mesmo percentual para a contribuição de $\mathrm{R} \$ 1,00$.

Para Roppa et al. (2007), os benefícios da arborização são muitas vezes de difícil valoração, o que pode tornar pequenas contribuições insignificantes diante de tal situação, mas que com o pouco de cada um adquire um valor razoável capaz de fazer muito pela arborização.

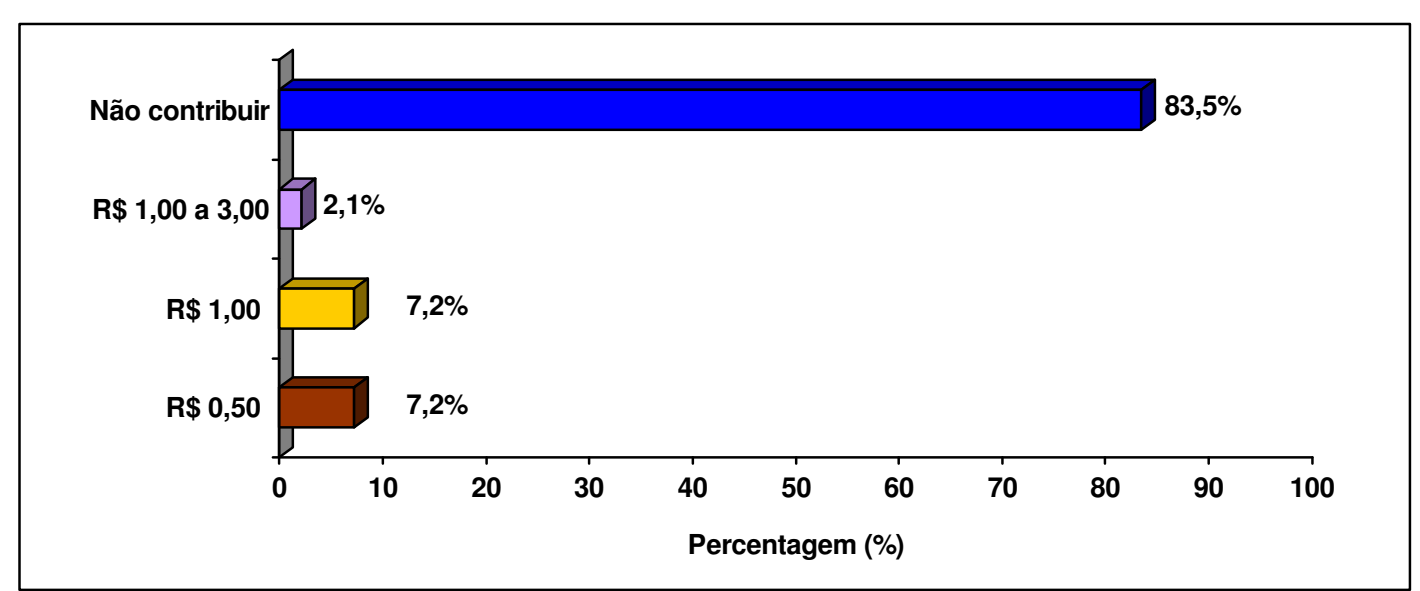

FIGURA 9. Possibilidade de contribuição financeira para manutenção da arborização do município, por residência, segundo a opinião dos entrevistados em São José de Piranhas (PB)

FIGURE 9 - Possibility of financial contribution for the maintenance of the tree planting in the town, per residence, according to the opinion of people interviewed in Sao Jose de Piranhas

\section{CONCLUSÕES}

Com essa pesquisa verificou-se que a população possui uma noção superficial sobre os benefícios da arborização, onde uma parcela considerável dos entrevistados não se mostrou disponível a colaborar.

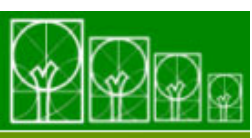

$\mathbf{S} \cdot \mathbf{B} \cdot \mathbf{A} \cdot \mathbf{U}$ Soc. Bras. de Arborização Urbana 
A arborização existente não foi planejada por parte dos órgãos competentes, cabendo aos moradores escolherem e manejarem as espécies. Os problemas da arborização urbana relatados pelos moradores são decorrentes de plantios realizados por eles próprios, não seguindo os padrões técnicos recomendados. Há necessidade de melhoria na arborização da cidade cuja tarefa deve ser desempenhada pela administração municipal em parceria com as Universidades, que deverão adotar critérios técnicos para seu planejamento e execução.

É necessário que os órgãos públicos promovam campanhas educativas de modo a sensibilizar a população sobre a importância da arborização para o meio em que estão inseridas e como podem usufruir dos benefícios de uma arborização adequada. Assim, a população consciente do processo será parceira na responsabilidade pelos cuidados com a arborização. O comprometimento e à participação da população local permitirá a definição e implantação de um Plano de Arborização que resulte em uma maior eficiência na utilização e manutenção do arboreto público e consequentemente em maior bem-estar social.

É preciso salientar a importância de trabalhos sobre a percepção da população que busquem verificar in loco a opinião dos residentes que constituirão dados importantes para a elaboração de um eficiente planejamento e manutenção da arborização urbana, principalmente em cidades da região semi-árida do Brasil.

\section{REFERÊNCIAS}

BATISTA, P. T. O meio ambiente, as cidades, as árvores urbanas e a SBAU. Sociedade

Brasileira de Arborização Urbana. Disponível em:

www.sbau.com.br/arquivos/materiais_paulo_tarso.htm. Acesso em outubro de 2006.

EMPRESA BRASILEIRA DE PESQUISA AGROPECUÁRIA - EMBRAPA. Sistema

Brasileiro de Classificação de Solos. Rio de Janeiro: Embrapa Solos, 2006. 306p.

FAGGIONATO, S. Percepção ambiental. Disponível em:

http://educar.sc.usp.br/biologia/textos/m_a_txt4.html>. Acesso em: 20 set. 2007.

GUZZO, P. Arborização Urbana. Disponível em:

<http://educar.sc.usp.br/biologia/prociencias/arboriz.html>. Acesso em 18 set. 2005.

IBGE.http://www.ibge.gov/estatística/população/censo 2000. Disponível na internet. Online.

01 de dezembro de 2008.

LIRA FILHO, J.A.; FONSECA, C.M.B.; ALVES, P.S.; LACERDA, R.M.A. Experiência piloto em arborização participativa em duas cidades de pequeno porte do semi-árido 
brasileiro. Revista da Sociedade Brasileira de Arborização Urbana, v.4, n.2, p.26-46, 2009.

MALAVASI, U.C.; MALAVASI, M. de M. Avaliação da arborização urbana pelos residentes estudo de caso em Mal. Cândido Rondon, Paraná. Revista Ciência Florestal, v.11, n.1, p.189-193, 2001.

MAROTI, P.S. Percepção Ambiental. Disponível em:

http://www.lapa.ufscar.br/portugues/perc_amb.htm.>. Acesso em: 20 set. 2005.

PAIVA, H.N.; GONÇALVES, W. Árvores para o ambiente urbano. Viçosa: Aprenda Fácil Editora, 2004. 180 p. 2442 p.

RIO, V. D.; OLIVEIRA, L. Percepção Ambiental - A Experiência brasileira. 2. ed. São Paulo: UFSCAR/Studio Nobel, 1999.

ROPPA, C; FALKENBERG, J.R.; STANGERLIN, D.M.; BRUN, F.G.K; BRUN, E.J.; LONGHI, S.J.1 Diagnóstico da percepção dos moradores sobre a arborização urbana na Vila Estação Colônia - Bairro Camobi, Santa Maria - RS. Revista da Sociedade Brasileira de Arborização Urbana, v. 2, n.2, p. 11-30, 2007.

SILVA, A.T.; TAVARES, T.S.; PAIVA, P.D.O.; NOGUEIRA, D.A. As praças Dr. Augusto Silva e Leonardo Venerando Pereira, Lavras - MG, segundo a visão dos seus freqüentadores. Ciência e Agrotecnologia, v. 32, n. 6, p.1701-1707, 2008.

TRIGUEIRO, A. Meio ambiente no século 21: 21 especialistas falam da questão ambiental nas suas nas suas áreas de conhecimento. Rio de Janeiro: Sextante, 2003. 368p 